\title{
Fatigue Fracture Analysis of Composite Plates with an Elliptical Hole
}

\author{
B. Kielbasa, ${ }^{\mathrm{a}, 1}$ P. Balon, ${ }^{\mathrm{a}, 2}$ A. Swiatoniowski, ${ }^{\mathrm{b}, 3}$ and J. Szostak ${ }^{\mathrm{b}, 4}$ \\ ${ }^{a}$ SZEL-TECH Szeliga Grzegorz, Mielec, Poland \\ b AGH University of Science and Technology, Department of Manufacturing Systems, Kraków, \\ Poland \\ ${ }^{1}$ bartek.kielbasa@gmail.com \\ 2 balonpawel@gmail.com \\ 3 swiatoni@imir.agh.edu.pl \\ ${ }^{4}$ szostak@agh.edu.pl
}

In this study, the analysis of fatigue fracture of composite plates with an elliptical hole having a longer axis parallel to the direction of the applied force is performed. The plates were made of glass/epoxy preimpregnate consisting of eight individual layers with the fiber configuration of $\left[+45^{\circ} \%-45^{\circ} /+45^{\circ} \%-45^{\circ}\right]_{S}$. The mechanical properties and material constants were assessed by performing static tensile tests and analytical calculations. The nominal fiber volume in the composite plates was experimentally determined. The test method of infrared passive thermography was implemented as a non-destructive testing, which provided the determination of the temperature distribution throughout the entire fatigue process. The thermograms were obtained and compared to the real-time photographs of the plates. Moreover, the specific results concerning fatigue phenomena and basic composite failure forms, which usually occur during the fatigue process, are discussed in detail. The theoretically predicted three individual fatigue fracture phases were corroborated the original test results. The first-ply failure (FPF) occurred in the local stress concentration area and propagated in the direction of the corners, along the fibers. The failure forms observed in the static and fatigue tests were nearly the same. Moreover, the comparative analysis of the fatigue fracture of laminates with three various types of holes was performed and presented in the graphical and tabular forms.

Keywords: fatigue analysis, composite materials, thermography, laminates.

Introduction. Composite material structures have many advantages over those made of conventional materials, but have some significant restrictions on their wide usage. One of their most critical drawbacks is a large number and variety of failure forms, which strongly affect the stiffness degradation and reduce the strength of the total structure. Composite materials are characterized by the gradual development of any failure. It is based on the fact that the failure starts with minor defects, which lead to the destruction of the whole structure over time [1]. Composites differ from the conventional metal materials by the evolution parttern of microcracks: the composite cracking process begins with the appearance of a single crack and its subsequent propagation. The sources of cracking are microscopic defects such as material porosity, fibrous ends, or the layer's structure. When the cracking propagates further, it can be accompanied by other failure forms, e.g., fiber cracking, matrix cracking, or fiber-matrix separation. All these failure forms qualify as microscopic defects. However, they affect both the micro- and macroscale material behavior. The following macroscale factors can be listed: (i) the load cycle frequency, (ii) the matrix and hardening's physicochemical properties, configurations and orientations of the individual layers, (iii) the type of load, and (iv) the environment conditions. All these aspects can have a crucial effect on the fatigue fracture development of the structure. The isotropic material failure is based on a single crack forming, which propagates deeper into 
the structure during the failure process and results in the reduced capabilities at the particular loads. The isotropic materials differ from the composite ones, the latter being distinguished by a compound fatigue fracture process, which consequently causes a macroscopic cracking of the structure.

Composite materials have much higher fatigue strength values than the conventional ones. Moreover, they also offer a greater safety in the event of a sudden occurrence of critical cracks. The composite failure scale is larger than that of the metal materials in the initial phase. However, composite materials have a higher cracking strength and capacity to withstand impact loads. Therefore, their durability is higher than that of conventional materials. It is noteworthy that the fatigue fracture metal materials is highly unpredictable due to the jumplike damage pattern at the final phase of the structure load capacity, while that of composite materials is gradual and often proportional, which makes their failure more predictable [2].

Fatigue Fracture Mechanisms of Composite Materials. Considering the composites' failure forms, four distinctive types can be distinguished. These are: matrix cracking, fiber cracking, delamination, and fiber-matrix separation. Each of the above failure forms will be described in detail in this section. The greater the number of fatigue cycles is, the greater changes are are observed the macroscale, e.g., the reduction of stiffness and strength. The mechanical properties, such as stiffness or strength of the composite materials, are greatly reduced under the cyclic loading conditions. The deterioration of these properties is highly dependent on the nature of the fatigue load or the type of laminate. Composites experience a gradual degradation of stiffness throughout the total fatigue process. The gradual degradation of the laminate stiffness makes it possible to monitor the unfavorable phenomena and accurately predict the structure damage [3,4]. Meanwhile, the conventional metal materials exhibit a high stiffness throughout the total fatigue process. A rapid degradation of stiffness can be observed only at the final stage of the process, when it is too late to predict the subsequent final failure.

Composite materials with fibrous development are made by fibers' bunches. Each individual fiber has its own permissible deformations, which vary from other fibers' deformations. Most often, this is caused by a difference in fiber diameter or production process defects. Cracking of individual fibers is caused by differences in the limiting values, which may result in the laminate's destruction. Consequently, the local stress concentrations are formed, which affect the damage of the adjacent fibers. It results in the accumulation of fiber cracks, which finally leads to the global damage of the laminate [5, $6]$.

Currently, the matrix strength is higher than that of fibers. Therefore, the fiber cracking in unidirectionally strengthened laminates occurs before the process of fibermatrix separation. The propagation direction of defects resulting from the fiber cracking is significantly dependent on the matrix and interfacial properties. At a further damage phase, if the bond between the fibers and matrix is strong, the matrix cracking can be observed. Otherwise, the laminate damage is reduced to fiber-matrix separations and further fiber cracking, which consequently lead to the total laminate failure. All the above damage forms refer to static and variable loads. The examples of fibers damaged during the fatigue loading are depicted in Fig. 1a.

Usually, the first failure form in composite materials impies microcracks of the matrix occurring inside the laminate and propagating along the direction of the fibers layout [7]. The matrix has a crucial role in composite materials. It is used, inter alia, to distribute stresses between individual fibers, stabilize the fibers, and increase the composite's impact strength. When the matrix is destroyed, all the above functions will cease. The matrix cracking very often leads to forming of delaminations. It is a failure form, which in the majority of cases occurs at the first stage of the fatigue damage. The matrix cracking is responsible for the loss of approx. $10 \%$ of the initial laminate stiffness. The laminate 
damage, which is initiated by matrix cracking at the first fatigue stage, has a significant impact on the further behavior of the structure. The matrix cracking usually begins at the point where the material defect is located and propagates along the fibers' layout. Considering composite materials composed of several layers of different configurations, it should be emphasized that the matrix cracking occurs in the weakest layer and propagates to the adjacent layers.

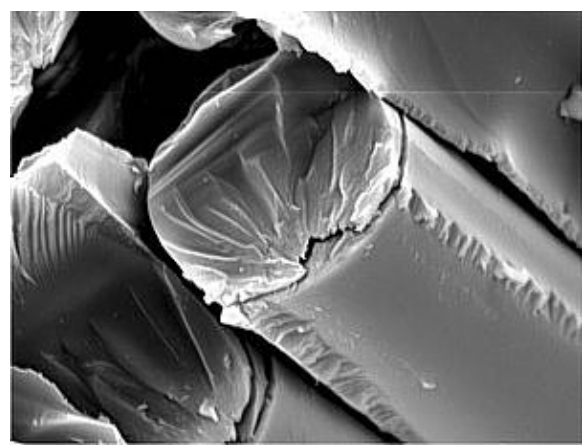

$\mathrm{a}$

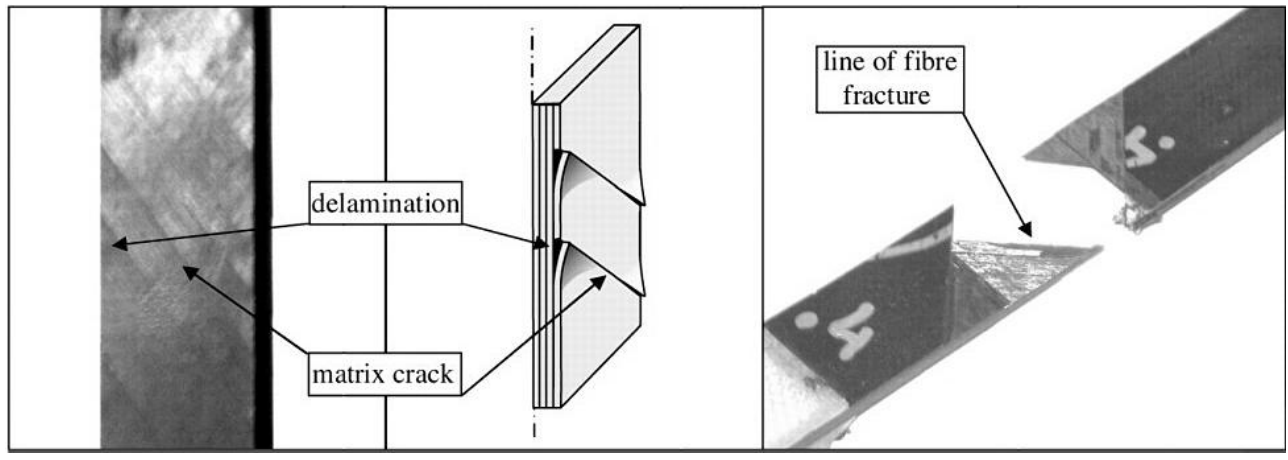

b

c

d

Fig. 1. Failure forms of a $\left[45_{2} / 90_{2} /-45_{2} / 0_{2}\right]_{S}$ laminate $[8,9]$.

One of the most significant drawbacks of composite materials is their susceptibility to delamination. This defect is the most common failure form, which limits the composite durability and is related to the separation of individual layers. Usually, the delamination is caused by stresses occurring between the individual layers of the laminate, mainly at the free edges, around the holes, corners, and near the internal material defects. The delaminations can be caused, for example, by the laminate manufacturing inaccuracy or sudden changes in the composite geometry [8].

Figure $1 \mathrm{~b}$ and $1 \mathrm{c}$ presents the matrix cracking places and the beginning of delamination at the free edge for the laminate with the fiber configuration of $\left[45_{2} / 90_{2} /-45_{2} / 0_{2}\right]_{S}$. The delamination propagates until the $-45^{\circ}$ and $0^{\circ}$ orientation layers are entirely separated, which leads to the global laminate failure (Fig. 1d).

Material Model. The composite plates made from the glass/epoxy preimpregnate (TVR $380 \mathrm{M} 12 / 26 \% /$ R-glass) were used in the experimental research. The density values of the particular phases are $\rho=2.56 \mathrm{~g} / \mathrm{cm}^{3}$ for the R-type fiber glass and $\rho=1.24 \mathrm{~g} / \mathrm{cm}^{3}$ for the M12 epoxy resin.

The composite was manufactured by the autoclave method using a vacuum bag. The subatmospheric pressure used in this method was 0,08 $\mathrm{MPa}$. The following parameters 
were defined during the cure process: curing time of $2 \mathrm{~h}$, work pressure of $0.4 \mathrm{MPa}$, heating and cooling gradient of $2{ }^{\circ} \mathrm{C} / \mathrm{min}$, and curing temperature of $135^{\circ} \mathrm{C}$.

The composites made by the autoclave method had eight individual layers and three different layer configurations, namely $0^{\circ}, 90^{\circ}$, and $\left[+45^{\circ} /-45^{\circ} /+45^{\circ} /-45^{\circ}\right]_{S}$. The test on determining the nominal fiber content of the laminate was conducted. It involved the cutting of six $50 \times 50 \mathrm{~mm}$ specimens (two specimens per each layer configuration), holding them in the oven for four hours at the temperature of $100^{\circ} \mathrm{C}$ with the subsequent precise weighing of the specimens. Then, the resin was removed by a burner, and the specimens were weighed one more time. It allowed to determine the volume and weight fraction of the fibers in the laminate. The results are presented in Tables 1 and 2 .

T a b 1 e 1

Volume Fractions of the Matrix and Fibers in the Glass/Epoxy Laminate

\begin{tabular}{||c|c|c|c|c|c|c|c||}
\hline $\begin{array}{c}\text { Volume } \\
\text { fraction }\end{array}$ & $\begin{array}{c}\text { Specimen 1 } \\
\left(0^{\circ}\right)\end{array}$ & $\begin{array}{c}\text { Specimen 2 } \\
\left(0^{\circ}\right)\end{array}$ & $\begin{array}{c}\text { Specimen 3 } \\
\left(90^{\circ}\right)\end{array}$ & $\begin{array}{c}\text { Specimen 4 } \\
\left(90^{\circ}\right)\end{array}$ & $\begin{array}{c}\text { Specimen 5 } \\
\left( \pm 45^{\circ}\right)\end{array}$ & $\begin{array}{c}\text { Specimen 6 } \\
\left( \pm 45^{\circ}\right)\end{array}$ & Average \\
\hline$V_{f}, \%$ & 65.75 & 67.73 & 66.97 & 65.11 & 68.35 & 66.37 & 66.71 \\
\hline$V_{m}, \%$ & 34.25 & 32.27 & 33.03 & 34.90 & 31.65 & 33.63 & 33.29 \\
\hline
\end{tabular}

Note. Here and in Table 2: $V_{f}$ is the fiber volume fraction in the composite, $V_{m}$ is the matrix volume fraction in the composite, $W_{f}$ is the fiber weight fraction in the composite, and $W_{m}$ is the matrix weight fraction in the composite.

T a b 1 e 2

Weight Fractions of the Matrix and Fibers in the Glass/Epoxy Laminate

\begin{tabular}{||c|c|c|c|c|c|c|c||}
\hline \hline $\begin{array}{c}\text { Weight } \\
\text { fraction }\end{array}$ & $\begin{array}{c}\text { Specimen 1 } \\
\left(0^{\circ}\right)\end{array}$ & $\begin{array}{c}\text { Specimen 2 } \\
\left(0^{\circ}\right)\end{array}$ & $\begin{array}{c}\text { Specimen 3 } \\
\left(90^{\circ}\right)\end{array}$ & $\begin{array}{c}\text { Specimen 4 } \\
\left(90^{\circ}\right)\end{array}$ & $\begin{array}{c}\text { Specimen 5 } \\
\left( \pm 45^{\circ}\right)\end{array}$ & $\begin{array}{c}\text { Specimen 6 } \\
\left( \pm 45^{\circ}\right)\end{array}$ & Average \\
\hline$W_{f}, \%$ & 79.85 & 81.25 & 80.71 & 79.39 & 81.68 & 80.68 & 80.53 \\
\hline$W_{m}, \%$ & 20.15 & 18.75 & 19.29 & 20.61 & 18.32 & 19.71 & 19.47 \\
\hline
\end{tabular}

Thickness of the plates was measured by the micrometer screw in each of the 75 measuring points. The average thicknesses of the plates are: $2.02 \mathrm{~mm}$ for plate $\mathrm{st}_{\mathrm{st}}, 2.03 \mathrm{~mm}$ for plate $\mathrm{zm}_{\mathrm{m} 1}$, and $2.03 \mathrm{~mm}$ for plate $_{\mathrm{zm} 2}$ (plate $\mathrm{st}_{\mathrm{st}}$ refers to the static tensile test, and plate $_{\mathrm{zm} 1}$ and plate $_{\mathrm{zm} 2}$ refer to the cyclic tests.)

Static Tensile Test of the Composite Specimens. In order to determine the material constants of the preimpregnate, the experimental method was implemented. The MTS 793 hydraulic machine with a maximum tensile force of $100 \mathrm{kN}$ was used to test twelve composite specimens by a static tensile test. Each specimen had eight individual layers, and the specific specimen groups differed from each other by the fiber configuration. As a result, the specimens were divided into groups as follows: 4 specimens with the fiber orientation of $0^{\circ}, 4$ specimens with the fiber orientation of $90^{\circ}$, and 4 specimens with the fiber orientation of $\pm 45^{\circ}$, which were the symmetrical laminate. In order to measure the transverse and longitudinal deformations, extensometers were used. The specimens having the fiber orientation of $0^{\circ}$ and $90^{\circ}$ had two extensometers placed on them. The first one was placed parallel to the fiber orientation, and the second one was placed perpendicular to them. The specimens having the fiber configuration of $\left[+45^{\circ} /-45^{\circ} /+45^{\circ} /-45^{\circ}\right]_{S}$ had only one extensometer, which measured the deformations in the direction of the applied load [10]. 
The described composite material possesses an orthotropic symmetry. Moreover, the plane stress state could be assumed because of the minor laminate thickness. Consequently, the conditions and relations corresponding to this kind of symmetry were used in the further calculations [11]:

$$
\left\{\begin{array}{l}
\sigma_{1} \\
\sigma_{2} \\
\tau_{12}
\end{array}\right\}=\left[\begin{array}{ccc}
Q_{11} & Q_{12} & 0 \\
Q_{12} & Q_{22} & 0 \\
0 & 0 & Q_{66}
\end{array}\right]\left\{\begin{array}{l}
\varepsilon_{1} \\
\varepsilon_{2} \\
\gamma_{12}
\end{array}\right\}, \quad \frac{v_{12}}{E_{1}}=\frac{v_{21}}{E_{2}},
$$

where $Q_{i j}$ are the stiffnesses reduced to the single layer plane in a local system.

These stiffnesses can be determined by the following relations:

$Q_{11}=\frac{E_{1}}{1-v_{12} v_{21}}, \quad Q_{22}=\frac{E_{2}}{1-v_{12} v_{21}}, \quad Q_{12}=\frac{v_{12} E_{2}}{1-v_{12} v_{21}}=\frac{v_{21} E_{1}}{1-v_{12} v_{21}}, \quad Q_{66}=G_{12}$.

Finally, the system of four equations was obtained

$$
\left\{\begin{array}{l}
\sigma_{1}^{0}=E_{1}\left(\varepsilon_{1}^{0}+v_{12} \varepsilon_{2}^{0}\right), \\
\sigma_{2}^{0}=E_{2}\left(\varepsilon_{2}^{0}+v_{21} \varepsilon_{1}^{0}\right)=0, \\
\sigma_{1}^{90}=E_{2}\left(\varepsilon_{1}^{90}+v_{21} \varepsilon_{2}^{90}\right), \\
\sigma_{2}^{90}=E_{1}\left(\varepsilon_{2}^{90}+v_{12} \varepsilon_{1}^{90}\right)=0 .
\end{array}\right.
$$

The stiffness modulus was calculated via the tangent of the inclination angle of the stress-strain curve linear part. The curve was obtained for the $\pm 45^{\circ}$ fiber orientation specimen. The following relation was used

$$
G_{12}=\frac{\sigma_{1}^{45}}{\varepsilon_{1}^{45}} .
$$

The static tensile test stresses were calculated based on the following relation:

$$
\sigma=\frac{F}{A}
$$

where $F$ is the tensile force (in N) and $A$ is specimen cross-sectional area (in $\mathrm{mm}^{2}$ ).

The displacement of the machine's piston was used to determine the length increment $\Delta l$. All calculations were made according to the ASTM D 638 standard.

Research Results. Table 3 presents the obtained elastic moduli and Poisson's ratios. Table 4 lists the stiffness moduli calculated via Eq. (5) and experimentally obtained from the extensometers. The discrepancies in the moduli measurements can be caused by the inaccuracy in the specimen axial setting in the machine's jaws or by inaccurate placements of the extensometers.

The curves presented in Fig. 2a show the stress-strain relationships during the tensile test of the $0^{\circ}$ fiber orientation plate. The curves are very similar for all four specimens. The stresses increased rapidly at the first process stage, while the strains increased very slowly according to the damage evolution pattern. After reaching about $85 \%$ of the ultimate tensile strength, the curve becomes almost flat, the force stabilizes, and the strain increase can be observed. For conventional ductile materials, this phase is called a plastic flow. At this 
$\mathrm{T}$ a b 1 e 3

The Experimental Elastic Moduli and Poisson's Ratios (Averaged Values)

\begin{tabular}{|c|c|c|c|}
\hline$E_{1}, \mathrm{GPa}$ & $E_{2}, \mathrm{GPa}$ & $v_{12}$ & $v_{21}$ \\
\hline 47.12 & 14.61 & 0.09 & 0.28 \\
\hline
\end{tabular}

$\mathrm{T}$ a b 1 e 4

A Comparison of Stiffness Moduli Calculated via Eq. (5) and Measured from the Displacements via Extensometers

\begin{tabular}{||c|c|c|c|c|c||}
\hline Rigidity modulus & Specimen 1 & Specimen 2 & Specimen 3 & Specimen 4 & Average \\
\hline $\begin{array}{c}G_{12}, \mathrm{GPa} \\
\text { (extensometer) }\end{array}$ & 15.97 & 15.78 & 14.89 & 15.04 & 15.42 \\
\hline $\begin{array}{c}G_{12}, \mathrm{GPa} \\
(\mathrm{MTS})\end{array}$ & 15.92 & 16.55 & 15.96 & 15.67 & 16.03 \\
\hline
\end{tabular}

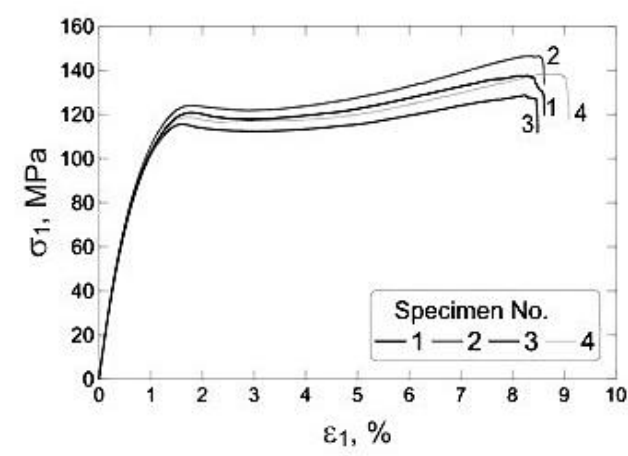

a

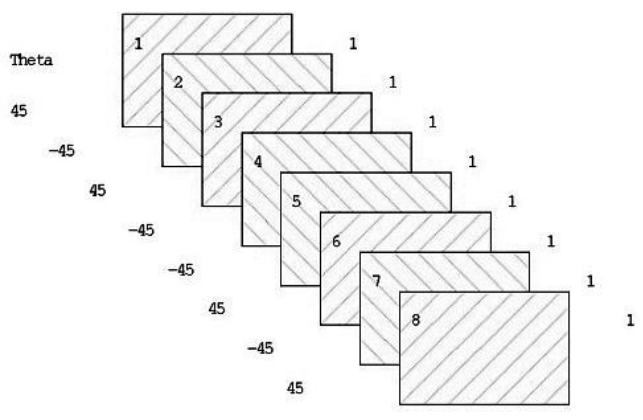

b

Fig. 2. Stress-strain plots for the $\pm 45^{\circ}$ fiber configuration laminate (a) and configuration of the individual layers in the laminate (b).

stage, the increase in the strain is not related to the stress increase (which actually exhibits a slight decrease). Further, the material recovers its ability to resist the applied external load, and this stage is called a plastic strengthening. This phase lasts until the maximum stress is reached, when the sudden stress drop is observed. This results in the total destruction of the laminate. The stress-strain curve exhibits a nonlinearity starting from the beginning of the process. The experimental research of the composite materials depends on many factors, and it can be claimed that the repeatability of the curves below is satisfactory.

The static tensile and fatigue tests were conducted for the glass/epoxy preimpregnate composite plates with a central elliptical hole. The symmetrical configurations $\left[+45^{\circ} /-45^{\circ} /+45^{\circ} /-45^{\circ}\right]_{S}$ of the layers are depicted in Fig. 2b. Each finished plate had additional holes drilled, and the cover plates were glued, in order to protect the structure from damage. The plate was mounted in the brackets with ten M10 bolts tightened with a torque of $36 \mathrm{~N} \cdot \mathrm{m}$ to obtain a uniform load distribution.

Figure 3 presents a view of the destroyed specimen after the tensile test. Lighter lines indicates the matrix cracking, which could be observed at the first stage of the process. The main failure form leading to the laminate damage was delamination, which initiated at the free edges of the specimen. At the final stage, the fiber-matrix separations and the motion of particular layers in relation to each other could be observed. 
$\mathrm{T}$ a b 1 e 5

Material Constants from the Experiment

\begin{tabular}{|c|c|c|c|c|c||}
\hline Value & Specimen 1 & Specimen 2 & Specimen 3 & Specimen 4 & Average \\
\hline$R_{m}, \mathrm{MPa}$ & 137.67 & 146.54 & 128.70 & 138.46 & 137.84 \\
\hline$\varepsilon_{1}^{d o p}, \%$ & 8.30 & 8.38 & 8.24 & 8.71 & 8.41 \\
\hline
\end{tabular}

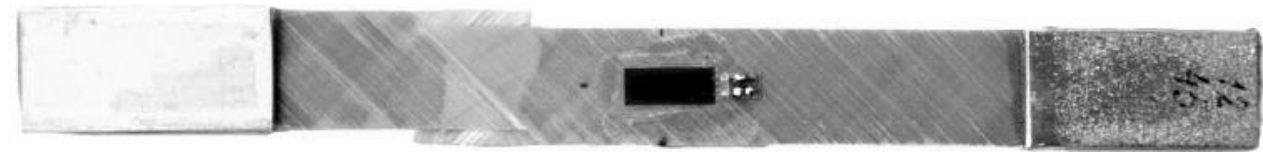

Fig. 3. One of the specimens failed after the tensile test.

Table 5 presents the experimental results, including the tensile strength and maximum permissible strains of the individual laminate specimens.

A Static Tensile Strength of the Composite Plate with an Elliptical Hole. The average load value, which was realized in the cyclic tests, was determined for comparing the static and fatigue fracture forms. Figure 4 presents the force-displacement curve for two plates subjected to the average cyclic load, and also for the statically tested plate. Initially, the plate $_{\text {st }}$ should have been damaged during the tensile test. This was impossible due to the improperly designed brackets, which became deformed during the test. Therefore, this plate's deformation is extremely high because it is the sum of the plate's elongation and the

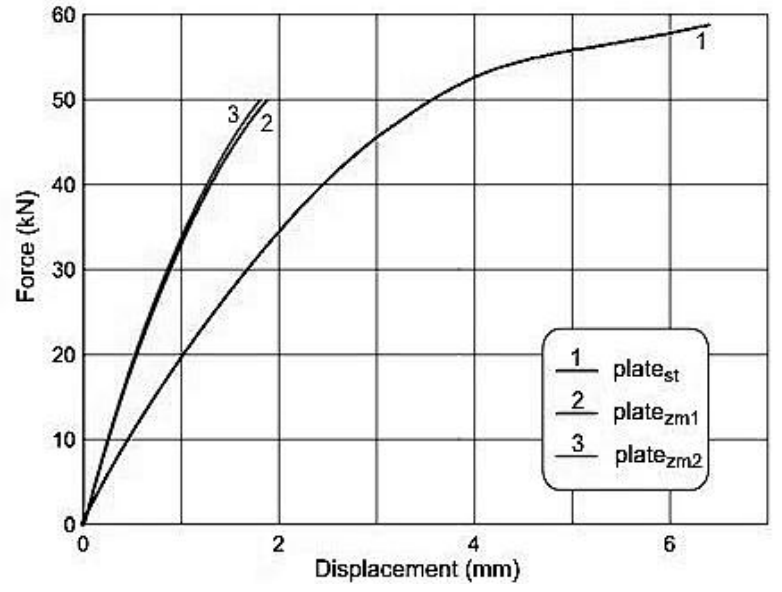

a

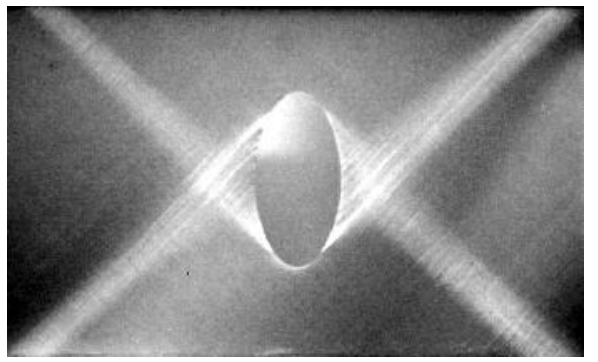

b

Fig. 4. Force-displacement curves for three tested composite plates: one subjected to static loading and two subjected to a cyclic one (a) and a side view on the damaged plate (b). 
brackets' deformation. The static tensile loading was conducted with a forced displacement of $0.5 \mathrm{~mm} / \mathrm{min}$. The loading process of the plate $\mathrm{zm}_{\mathrm{m} 1}$ and plate $\mathrm{zm}_{2}$ ran properly because the brackets were properly set (additional pressure plates were added). During these tests, the tensile force increased in time, and it was $9 \mathrm{kN} / \mathrm{min}$. The curves for plate $\mathrm{zm}_{1}$ and plate $_{\mathrm{zm} 2}$ were obtained by loading the plates to the average value of the cyclic load.

Fatigue Fracture of the Composite Plates with an Ellipical Hole. The cyclic tests were conducted using an MTS 793 hydraulic strength machine. A cycle of unidirectional pulsed tensile loads was implemented. At the first stage of the process, the plate $\mathrm{zm}_{\mathrm{m} 1}$ was loaded by the average cyclic load of $50 \mathrm{kN}$. Further, the fatigue test started by implementing a load with a variable force and frequency of $30 \mathrm{~Hz}$. The force amplitude was $5 \mathrm{kN}$. Overal, 270,000 cycles were executed, which led to the total destruction of the composite plate. The plate $_{\mathrm{zm} 2}$ was also initially loaded to the average load value of $50 \mathrm{kN}$. The force amplitude was slightly reduced, and equaled $4 \mathrm{kN}$, so the load force value oscillated in the range of $46-54 \mathrm{kN}$ with a frequency of $30 \mathrm{~Hz}$. This time, the laminate damage was obtained after 1651,871 cycles. The amplitude change from 5 to $4 \mathrm{kN}$ significantly determined the plate strength and durability.

Figure 5 presents the examples of hysteresis loops for the plate $\mathrm{zm}_{1}$ and plate $_{\mathrm{zm} 2}$ obtained during the fatigue tests, which were used to determine the stiffness degradation of the tested laminates.

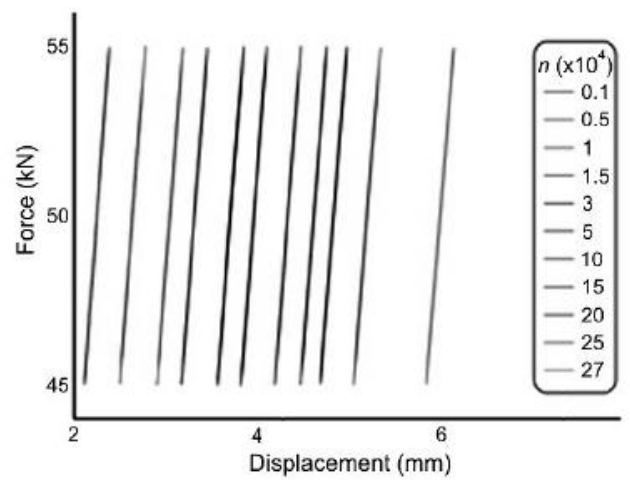

a

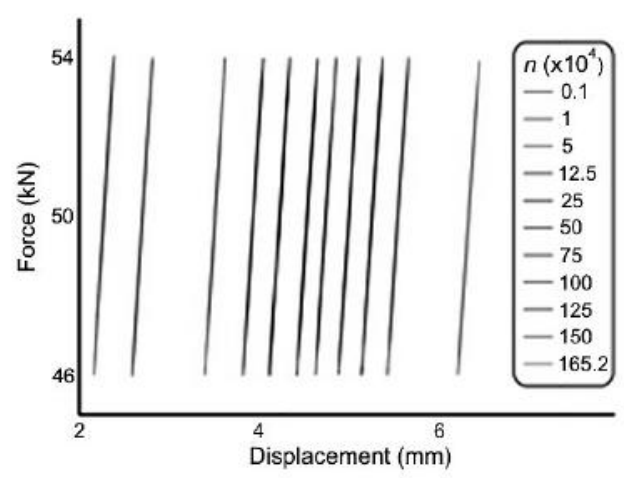

b

Fig. 5. Exemplary hysteresis loops for plate $\mathrm{zm} 1_{1}$ (a) and plate $\mathrm{zm}_{2}$ (b).

The characteristic curves of the stiffness degradation for the plate $\mathrm{zm}_{\mathrm{zm} 1}$ and plate $_{\mathrm{zm} 2}$ are depicted in Fig. 6. The horizontal axis is the ratio of realized $n$ cycles to the number of cycles, which caused the laminate damage, $N_{f}$. The vertical axis presents the ratio of stiffness modulus to the static stiffness modulus determined for $n=0$.

The experimental results are compatible to the theorerical ones, whereas the reduction of plate stiffness is observed throughout the entire fatigue process. A sudden stiffness degradation at the first fatigue stage, followed by a further stabilization, can be observed for both plate $\mathrm{zm}_{\mathrm{z} 1}$ and plate $\mathrm{zm} 2_{2}$. After reaching 50,000 cycles for the plate $\mathrm{zm}_{\mathrm{z} 1}$, strains slowly decrease, and the curve runs linearly until the number of 200,000 cycles is reached. Then, a sudden laminate stiffness degradation occurs, and the strains increase (Fig. 7). The curve obtained for the plate $\mathrm{zm} 2_{2}$ has a similar pattern. Despite the large difference in the number of cycles between the two plates, their deformation patterns are similar. At the first process phase (phase I), the laminate deformations increase, and the number of cycles is low. Then, the curve stabilizes, and the deformations increase gradually (phase II). At the final phase (phase III), a sudden deformation increase can be observed, which results in a total laminate destruction. 


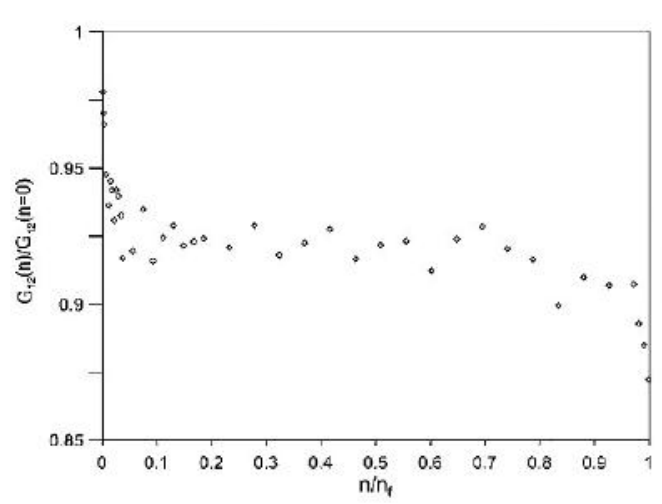

a

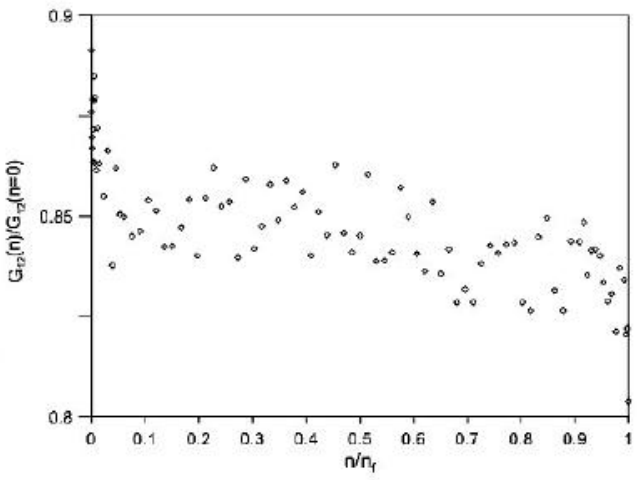

b

Fig. 6. Laminate stiffness degradation accordingly for the plate $\mathrm{zm} 1_{\text {(a) }}$ and plate $\mathrm{zm}_{2}$ (b).

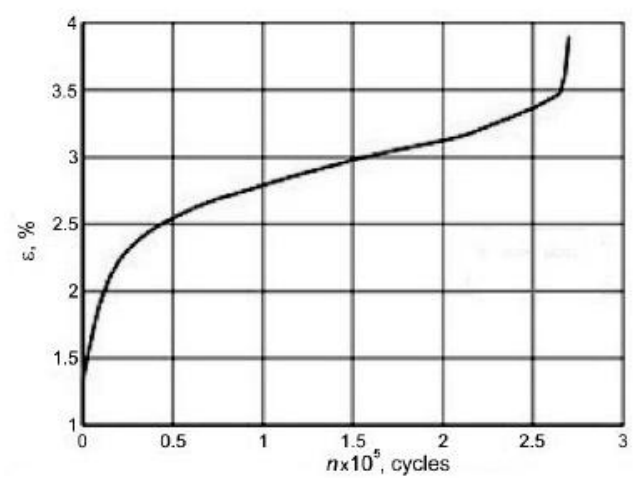

a

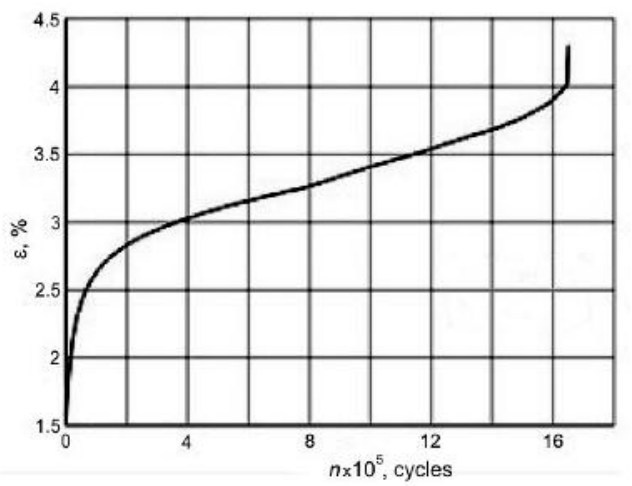

b

Fig. 7. Deformations increase dependent on the cycles number for plate $\mathrm{zm} 1_{\text {(a) }}$ and plate $\mathrm{zm} 2_{2}$ (b).

Non-Destructive Testing of an Infrared Passive Thermography. In order to obtain as much information as possible, the plates were photographed throughout the entire fatigue process, and the infrared passive thermography method was implemented. A thermovision camera FLIR A324 and the ThermaCAMResearcher Pro software was used in the experiment [12]. A phenomenon of thermal energy dissipation into the atmosphere is caused by an initiation and propagation of the laminate damage. Due to recording of the local temperature increase via an IR camera, further fatigue fracture analysis was possible. Tables 6 and 7 present a comparison of photographs and thermographs for plate $_{\mathrm{zm} 1}$ and plate $\mathrm{zm}_{\mathrm{m} 2}$ for particular cycle numbers. The failure initiation is very similar for both plates.

At the early stages of the failure, surroundings of the hole are damaged first due to the local stress concentrations area. Then, the failure propagates in the corner direction. Light color along the diagonals responses for the matrix cracking in the initial damage phase. This phenomenon can be observed in the photographs presenting appropriately 50,000 cycle number for plate $_{\mathrm{zm} 1}$ and 100,000 cycle number for plate $\mathrm{zm}_{\mathrm{zm}}$. Early matrix-fiber separations and local delaminations in hole's neighbourhood can be observed for plate $\mathrm{zm}_{\mathrm{m} 1}$ at the 50,000 cycle number already. This phenomenon occurs for plate $\mathrm{zm} 2_{2}$ at the cycle number of 100,000. Cycle amount of appropriately 150,000 for plate $\mathrm{zm} 1_{\mathrm{z} 1}$ and 600,000 for plate $\mathrm{zm} 2_{2}$ led to significant and visible damage of the laminates, where the failure caused by matrix-fiber 
$\mathrm{T}$ a b 1 e 6

A Comparison of Photographs and Thermograms of the Plate ${ }_{\mathrm{zm} 1}$ Fatigue Process

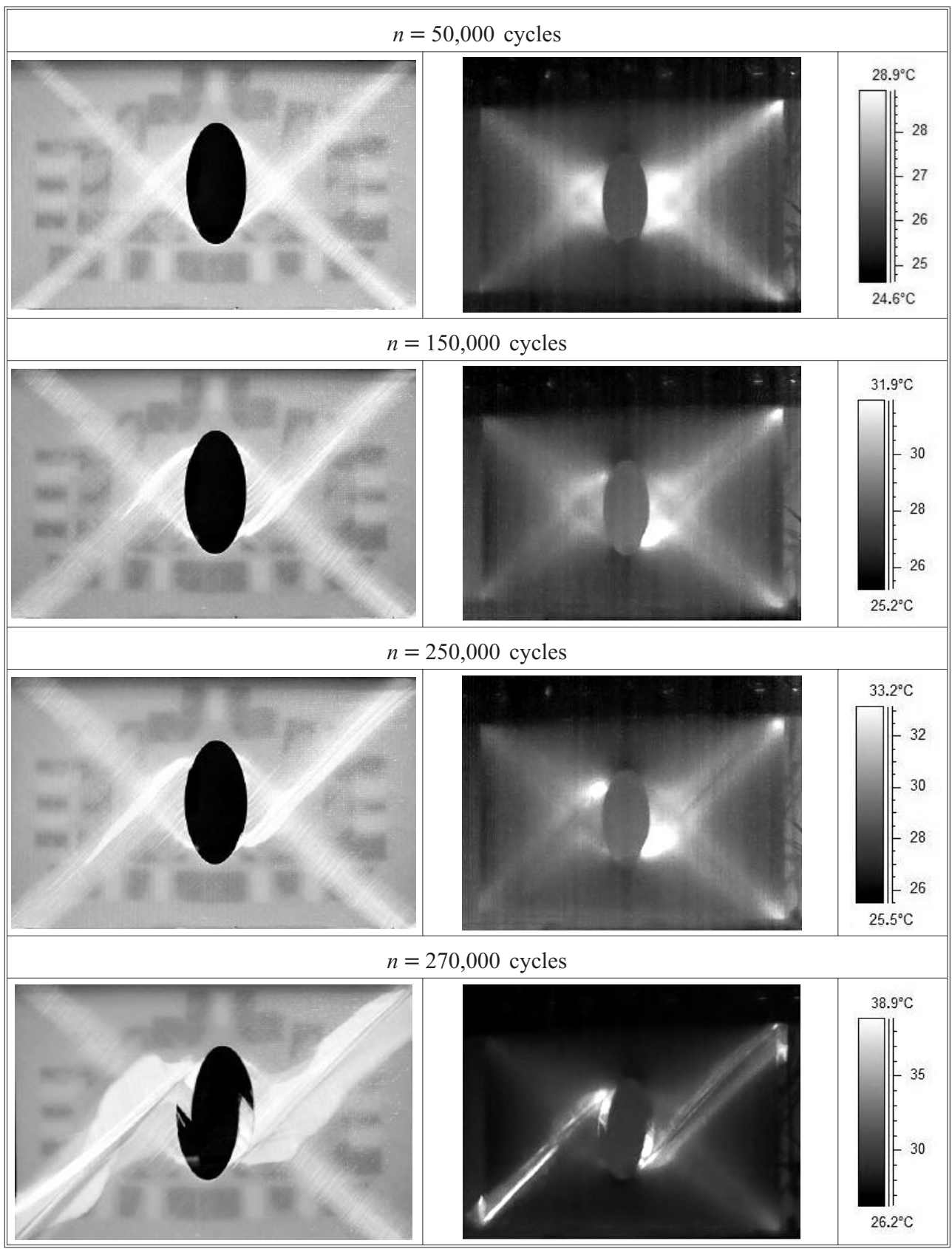

separations is large. It is worth to emphasize that the temperature decrease can be observed for this process moment. It is caused by a lack of possibilities to dissipate the energy into the atmosphere. The final process phase leads to the total destruction of the laminates and large temperature increases, which is presented in the thermograms below.

The graphs below present the differences between minimum and maximum temperature recorded around the elliptical holes (Fig. 8). Increase and decrease of the temperatures depended on the failure forms which occurred at the particular time of the fatigue process. 
$\mathrm{T}$ a b 1 e 7

\section{A Comparison of Photographs and Thermograms of the Plate ${ }_{\mathrm{zm} 2}$ Fatigue Process}

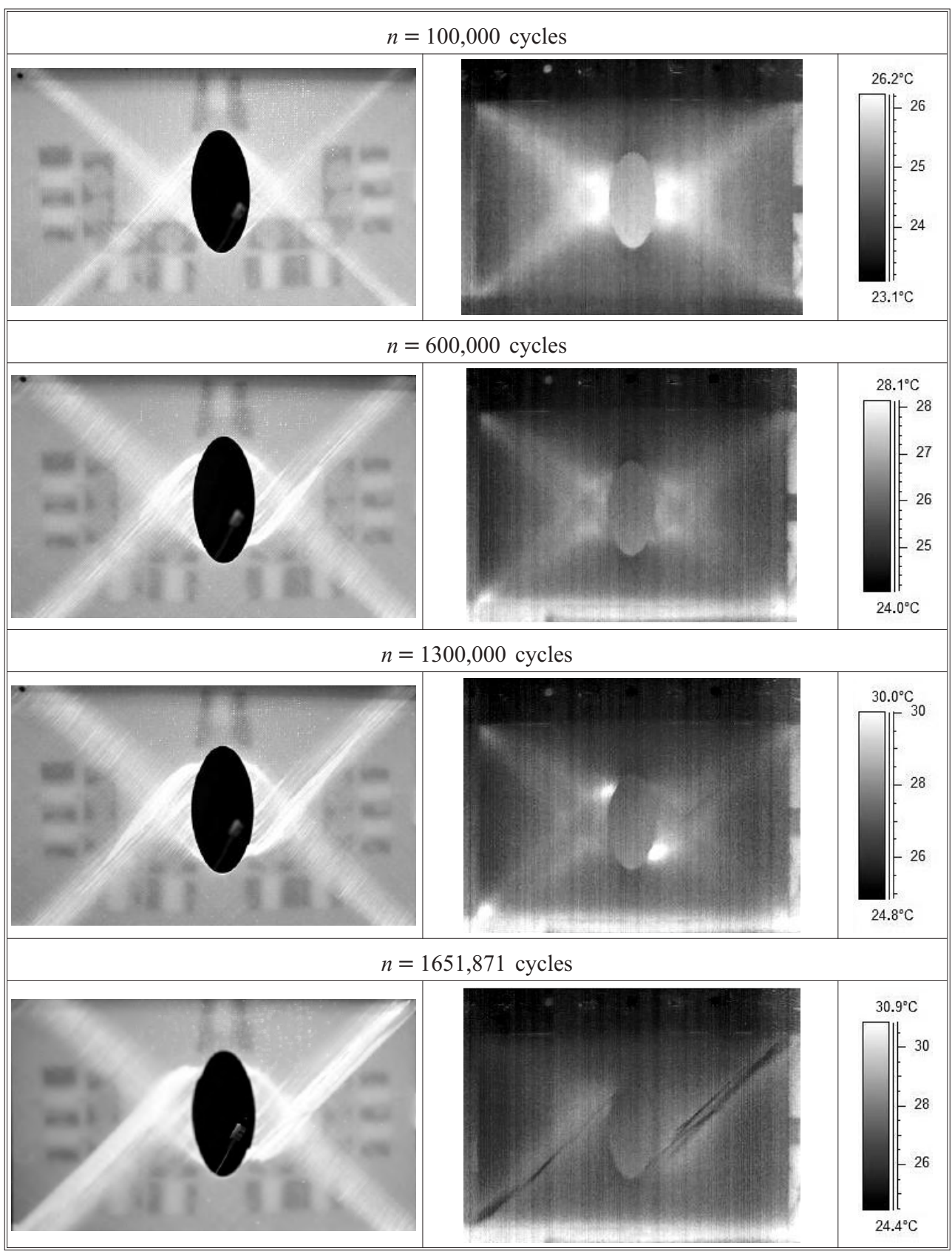

At the large amount of matrix-fiber separations, the temperature around the holes decreased gradually. With the growth of the cycle number, the plate temperature increased, and the temperature difference increased as well, which can be observed below. In the early process phase, a sudden rise of the temperature gradient can be observed. Then, the gradient decreases, and finally the temperature difference increases with the gradual increase of the cycle number. The plates were not being destroyed perfectly symmetrically, which could affected the non-uniform character of the discussed curves. With less 


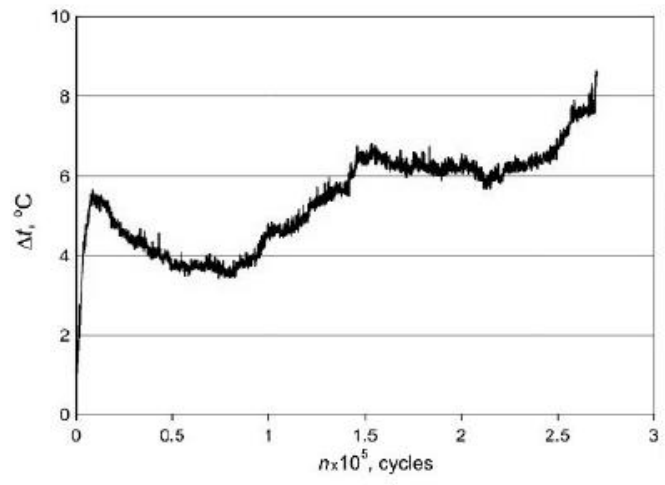

a

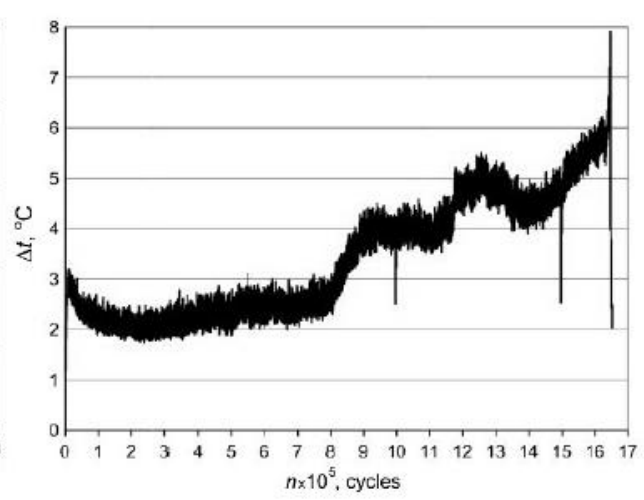

b

Fig. 8. Curves presenting the differences between minimum and maximum temperatures around the elliptical hole appropriately for plate $\mathrm{zm} 1_{\mathrm{z}}$ (a) and plate $_{\mathrm{zm} 2}$ (b).

amplitude forced, the temperature difference is less than when using a higher amplitude, as for plate $\mathrm{zm}_{\mathrm{zm}}$. Therefore, the intensity of the load applied influences both the total number of cycles causing the laminate destruction, but also the temperature layout throughout the research.

A Comparison of the Research Results. This chapter contains a comparison of the experimental research results which were conducted for the composite plates having a circular and elliptical hole. Overally, six plates were tested, two of which had a circular hole, two an elliptical hole with a longer axis parallel to the direction of forces, and two plates also had an elliptical hole but with a longer axis perpendicular to the direction of forces. For the results comparison, one of each plate type was used.

The graph above presents the dependence of deformations increase and cycle number curves for the three plates with various holes (Fig. 9a). The curve which differs extremely from the others concerns the plate having a circular hole. This difference caused by the fact that this experiment was divided into three days, due to the restrictions of the machine working time (the work parameters were the same). In the initial fatigue phase, a sudden strains increase appears at low cycles number and is observed for all the plates (phase I). Next, the curve run stabilizes and the deformations increase very slowly (phase II), and in the final stage it leads to the overall damage of the laminate (phase III). However, this curve does not reflect the correct nature of the curve due to the experiment's division on over three days, which resulted in staggering of the laminate deformations. The plate having an elliptical (horizontal) hole was not totally damaged, which was caused by a limited working time of the strength machine (the experiment lasted from morning till night). The cycles number of 1500,000 was not enough to destroy the laminate. The curve for the plate having an elliptical (vertical) is almost the same as for the previously described plate. Three failure phases which are typical for composite materials can be distinguished. However, the curve of the plate having a vertical elliptical hole is more stabilized and the failure phases are easier to observe and distinguish.

Figure $9 \mathrm{~b}$ presents the stiffness degradation chart for the plates having three various holes. The curves are greatly similar to one another. In the initial process phase, a sudden stiffness degradation can be observed for the plates having elliptical holes. The plate having a circular hole has a stabilized and smooth curve in the initial process stages. This curve shows a slow and gradual degradation of the laminate stiffness throughout the whole fatigue fracture process. The curves for elliptical holes stabilize after exceeding the first phase of the sudden stiffness decrease, and the degradation proceeds slowly and gradually. 


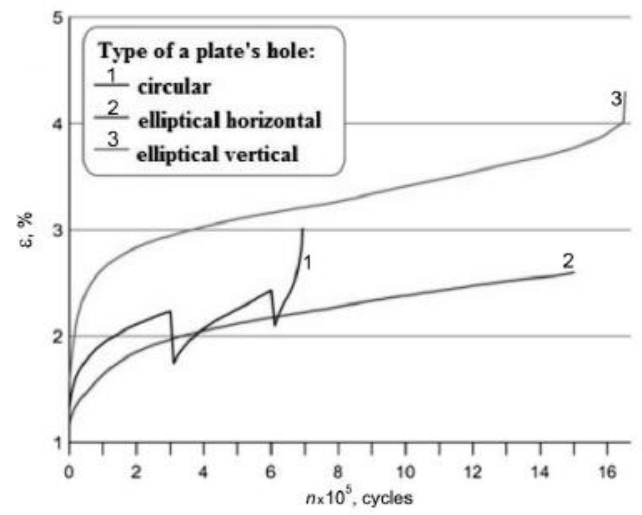

a

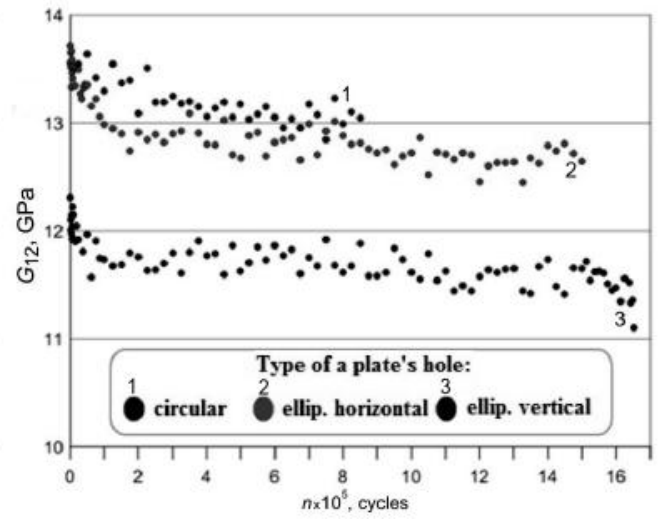

b

Fig. 9. Deformations increase dependent on the cycles number for three plates with various hole type (a); a comparison of laminate stiffness degradation for three various hole types (b).

In a static tensile test of the specimens, the average obtained rigidity moduli values equaled appropriately $15.42 \mathrm{GPa}$ for the extensometers and $16.03 \mathrm{GPa}$ for the strength machine.

The plate having a horizontal hole has the lowest average load value, which could affected its relatively low damage compared to the other plates (Fig. 10). All the plates had the same force amplitude of $4 \mathrm{kN}$. The plate with a circular hole varied from the other
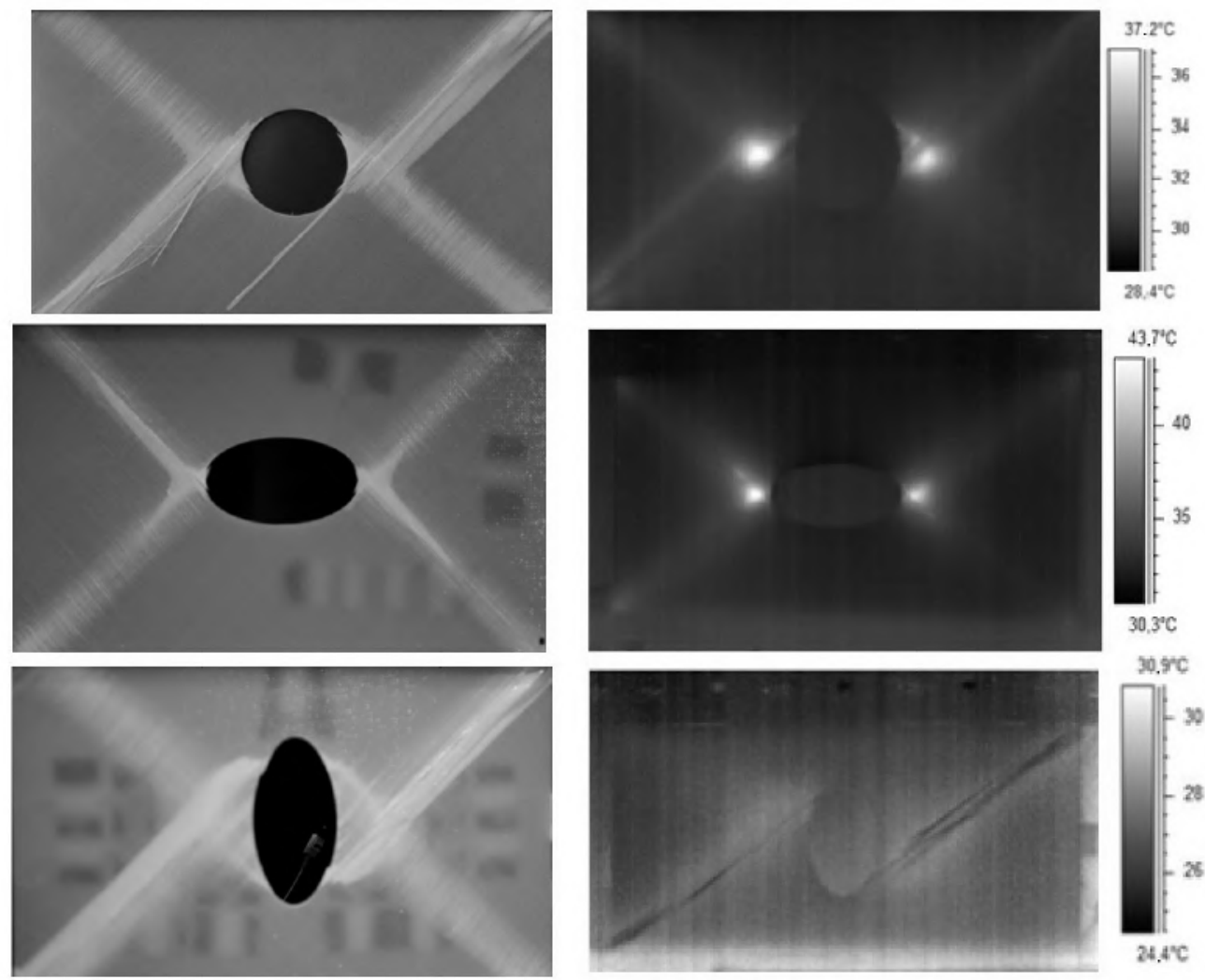

Fig. 10. A comparison of the plates having various hole just before the destruction moment. 
plates by a frequency value which equaled $15 \mathrm{~Hz}$, and for the elliptical holes $30 \mathrm{~Hz}$. The failure forms of all plate types were compared to their appropriate thermograms. The plate having a circular hole was destroyed after 692,565 cycles, the plate having a horizontal elliptical hole after 1500,000 cycles, and the plate having a vertical elliptical hole after 1651,871 cycles. The fatigue damage process was similar for all composites. Initially, some local fiber-matrix separations could be observed, and also local delaminations. Further, the damage propagated to the plate corners and large areas of fiber-matrix separations were visible (especially for the plates with circular and vertical holes), which finally led to the destruction of the whole laminate.

In contrast to the above results of this section, Table 8 presents a comparison of all plates with three various hole types (two plates per each hole type). The experience gained from the subsequent tests and studies provided a deeper insight into the selection of the research parameters and estimation of the composite failure forms. The results on the plates with a circular hole were the least satisfactory due to the test execution being expanded over three days. Because of the too low fatigue load value, the plates having an elliptical horizontal hole were not completely destroyed (Table 8 ).

T a b 1 e 8

A Comparison of the Parameters for All Composite Plates

\begin{tabular}{||c|c|c|c|c|c|c||}
\hline \hline Type of hole & \multicolumn{2}{|c|}{ Circular } & \multicolumn{2}{c||}{ Elliptical horizontal } & \multicolumn{2}{c||}{ Elliptical vertical } \\
\hline Plate number & plate $_{\mathrm{zm} 1}$ & plate $_{\mathrm{zm} 2}$ & plate $_{\mathrm{zm} 1}$ & plate $_{\mathrm{zm} 2}$ & plate $_{\mathrm{zm} 1}$ & plate $_{\mathrm{zm} 2}$ \\
\hline $\begin{array}{c}\text { Cycle number } \\
n_{g r} \times 10^{5}, \text { cycles }\end{array}$ & 4.4 & 6.9 & 8.5 & 15 & 2.7 & 16.5 \\
\hline $\begin{array}{c}\text { Temperature } \\
\text { difference } \Delta t,{ }^{\circ} \mathrm{C}\end{array}$ & 11.4 & 4.9 & 8.3 & 16.3 & 9.6 & 5.6 \\
\hline \hline
\end{tabular}

Conclusions. This paper describes an analysis of composite plates fatigue fracture with a centrally located horizontal elliptical hole. The plates were manufactured from the glass/epoxy preimpregnate. The experimental research description and failure analysis by the non-destructive method of infrared passive thermography are presented. This method allowed for the assessment of a laminate damage development in a precise and effective way. At the final fatigue process phase which led to the structure failure, a large temperature increase was observed over the composite's entire surface. The stiffness degradation proceeded gradually during the whole fatigue process. However, the stiffness decreased rapidly in the first process phase, and then stabilized afterwards. As a confirmation of the theoretical knowledge, the existence of three individual fatigue fracture phases was confirmed by the experimental research. Moreover, the nominal fiber content of the composite was experimentally determined. The FPF damage, which occurred in the local stress concentration areas, started to propagate in the direction of the corners along the fiber layout. Very similar failure forms were observed the static tensile and fatigue tests.. The results presented in this paper will surely encourage scientists to research the multilayered structures on a wider scale and under various loading conditions, providing more knowledge and experience on the failure forms of the laminates and the selection of the research parameters. This will be instrumental to the further research of composites.

1. Y. Zhou, L. Yang, and Y. Huang, Micro- and Macromechanical Properties of Materials, Taylor and Francis Group (2014).

2. A. Muc, P. Kedziora, and M. Barski, Konstrukcje i Materialy Kompozytowe Problemy i Zadania - Część II, Cracow University of Technology, Cracow (2011). 
3. M. R. Jones, Mechanics of Composite Materials, Script Book Company, Washington (1975).

4. I. Milne and B. L. Karihaloo (Eds.), Compehensive Structural Integrity, Vol. 3: R. de Borst and H. A. Mang, Numerical and Computational Methods, Elsevier (2003).

5. S. W. Tsai and E. M. Wu, "A general theory of strength for anisotropic materials," $J$. Compos. Mater., 5, 58-80 (1971).

6. M. Megel, L. Kumosa, T. Ely, et al., "Initiation of stress-corrosion cracking in unidirectional glass/polymer composite materials," Compos. Sci. Technol., 61, No. 2, 231-26 (2001).

7. J. A. Nairn, "Matrix microcracking in composites," in: R. Talreja and J.-A. E. Manson (Eds.), Polymer Matrix Composites, Vol. 2: Comprehensive Composite Materials, Elsevier Science (2000), pp. 403-432.

8. M. R. Wisnom, "The role of delamination in failure of fibre-reinforced composites," Philos. T. R. Soc. A, DOI: 10.1098/rsta.2011.0441 (2012).

9. J. Summerscales, Composites Design and Manufacture, Plymouth University teaching support materials (2005).

10. W. S. Tsai, Theory of Composite Design, Think Composites, Dayton (1992).

11. M. Z. Siddiqui, F. Tariq, N. Naz, and M. F. Ahmed, "Determination of Young's modulus of metallic and composite materials by digital image correlation," J. Space Technol., 1, 32-37 (2012).

12. D. P. Pastuszak, Failure Analysis of Composite Structures by Thermography, Cracow University of Technology, Cracow (2015). 